\title{
Creep and Fatigue Interaction Behavior in Sanicro 25 Heat Resistant Austenitic Stainless Steel
}

\author{
Mattias Calmunger, Guocai Chai, Sten Johansson and Johan Moverare
}

\section{Linköping University Post Print}

\section{Tweet}

N.B.: When citing this work, cite the original article.

The original publication is available at www.springerlink.com:

Mattias Calmunger, Guocai Chai, Sten Johansson and Johan Moverare, Creep and Fatigue Interaction Behavior in Sanicro 25 Heat Resistant Austenitic Stainless Steel, 2016, Transactions of the Indian Institute of Metals, (69), 2, 337-342.

http://dx.doi.org/10.1007/s12666-015-0806-3

Copyright: Springer Verlag (Germany)

http://www.springerlink.com/?MUD=MP

Postprint available at: Linköping University Electronic Press

http://urn.kb.se/resolve?urn=urn:nbn:se:liu:diva-123646 


\title{
Creep and fatigue interaction behavior in Sanicro 25 heat resistant austenitic stainless steel
}

\author{
Mattias Calmunger ${ }^{1}$, Guocai Chai ${ }^{1,2 *}$, Sten Johansson ${ }^{1}$, and Johan Moverare ${ }^{1}$ \\ ${ }^{1}$ Engineering Materials, Linköping University, 58183 Linköping, Sweden \\ ${ }^{2}$ Sandvik Materials Technology, SE-811 81 Sandviken, Sweden \\ *Corresponding author e-mail: guocai.chai@sandvik.com
}

\begin{abstract}
Sanicro 25 is a newly developed advanced high strength heat resistant austenitic stainless steel. The material shows good resistance to steam oxidation and flue gas corrosion, and has higher creep rupture strength than other austenitic stainless steels available today. It is thus an excellent candidate for superheaters and reheaters for advanced ultra-super critical power plants with efficiency higher than $50 \%$. This paper provides a study on the creep-fatigue interaction behavior of Sanicro 25 at $700{ }^{\circ} \mathrm{C}$. Two strain ranges, $1 \%$ and $2 \%$, and two dwell times, 10 and 30 minutes, were used. The influences of dwell time on the cyclic deformation behavior and life has been evaluated. Due to stress relaxation the dwell time causes a larger plastic strain range compared to the tests without dwell time. The results also show that the dwell time leads to a shorter fatigue life for the lower strain range, but has no or small effect on the life for the higher strain range. Fracture investigations show that dwell times result in more intergranular cracking. With the use of the electron channeling contrast imaging (ECCI) technique, the influences of dwell time on the cyclic plastic deformation, precipitation behavior, recovery phenomena and local plasticity exhaustion have also been studied.
\end{abstract}

Key Words: Sanicro 25, Advanced ultra-super critical power plant, Creep, Low cycle fatigue, Cyclic plastic deformation.

\subsection{INTRODUCTION}

For the next generation energy production advanced ultra-super critical (A-USC) thermal power plants are believed to be of high importance since they have efficiencies above $50 \%$. The high efficiency is mainly attributed to the increased temperature $\left(700{ }^{\circ} \mathrm{C}\right)$ and pressure (35 MPa). For the highest temperatures, which are found in the superheaters and reheaters, materials are necessary to provide sufficient creep strength in presence of corrosive environments of the flue gases on the fireside and resist steam oxidation on the internal tube surfaces $[1,2]$.

Austenitic stainless steels have previously been used for components in USC thermal power plants [1-3]. Normally, advanced austenitic stainless steels are designed to withstand temperatures up to $650{ }^{\circ} \mathrm{C}$. Sandvik Sanicro ${ }^{\mathrm{TM}} 25$ (Sanicro 25) is a newly developed advanced high strength heat resistant austenitic stainless steel. Sanicro 25 possess good resistances to steam oxidation and flue gas corrosion, and has higher creep rupture strength than other austenitic stainless steels available today [4-6]. Thus, it is an excellent candidate for superheaters and reheaters for A-USC power plants.

Recently the low cycle fatigue (LCF) properties at $700{ }^{\circ} \mathrm{C}$ of Sanicro 25 have been reported $[7,8]$. However, the influence of dwell time in combination with LCF, the creep-fatigue interaction is not yet fully understood. 
This paper provides a study on the creep-fatigue interaction behavior of Sanicro 25 at a temperature of $700{ }^{\circ} \mathrm{C}$. The influence of dwell time on the cyclic deformation behavior and cyclic life is evaluated. The electron channeling contrast imaging (ECCI) technique is used to characterize the influence of dwell time on the cyclic plastic deformation, precipitation behavior, recovery phenomena and introduction of local plasticity in the microstructure.

\subsection{EXPERIMENAL}

\subsection{SANDVIK SANICROTM 25}

The investigated material originates from an extruded solid cylinder, with a chemical composition of Fe-22.3Cr-25.0Ni-3.4W-3.0Cu-1.4Co-0.5Nb-0.5Mn-0.24N-0.07C in wt.\%. Before the manufacturing of the specimens the material was solution heat-treated, at a temperature of $1250{ }^{\circ} \mathrm{C}$ for $10 \mathrm{~min}$ followed by water quenching. A round bar LCF-specimen with a gauge length of $15 \mathrm{~mm}$ and a diameter of $10 \mathrm{~mm}$ was used. The microstructure of Sanicro 25 prior to the deformation is shown in Fig. 1. The tested Sanicro 25 had an average grain size of ASTM 2.5 prior to testing, but contains a mixture of both larger and smaller grains as shown in Fig.1.

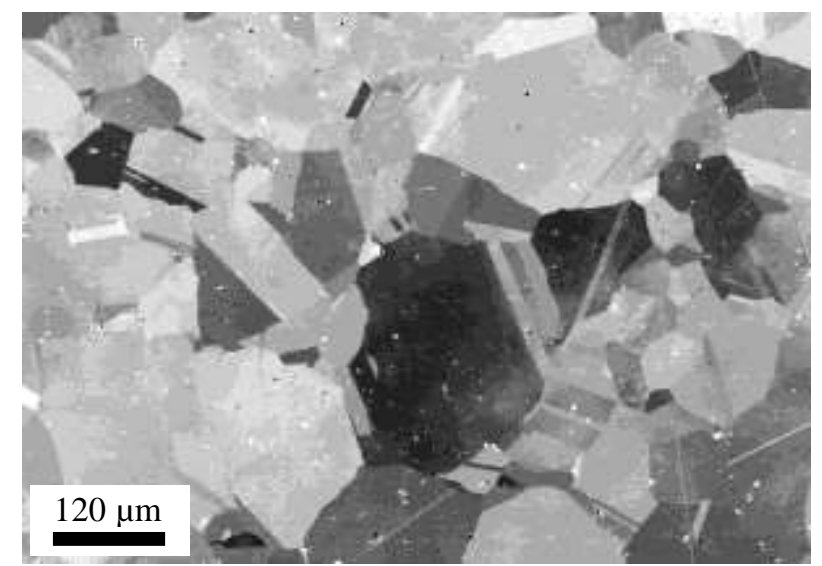

Fig.1: Microstructure of Sanicro 25 prior to deformation.

\subsection{CREEP-FATIGUE INTERACTION TESTING}

An MTS servo hydraulic testing machine equipped with an Instron 8800 control system, an Instron 2632-055 extensometer together with an MTS 652.01 furnace were employed for the creep-fatigue interaction testing. All tests were run under strain control at two different strain ranges, $1 \%$ and $2 \%$. The testing was performed at $700{ }^{\circ} \mathrm{C}$ and two dwell times, 10 and 30 minutes, were applied at the maximum strain in tension and compression.

\subsection{SCANNING ELECTRON MICROSCOPY}

To image local misorientation, defects and strain fields as contrast variations, the electron channeling contrast imaging (ECCI) technique uses the interaction between backscattered electrons and the crystal planes [9-11]. For the ECCI observations, a HITACHI SU-70 field emission gun-scanning electron microscope (FEG-SEM) and a Zeiss XB 1540 FEG-SEM were used. ECCI was performed at $10 \mathrm{kV}$ acceleration voltage and a working distance of 7 and $5 \mathrm{~mm}$, using solid state 4-quadrant BSD detectors. 


\subsection{RESULTS AND DISCUSSIONS}

\subsection{INFLUENCE OF DWELL TIME ON FATIGUE LIFE}

A clear difference in the influence of dwell time on of the number of cycles to failure was observed between the lower $(1 \%)$ and the higher $(2 \%)$ strain range. The criterion used for the number of cycles to failure is based on a $10 \%$ load drop. Figure 2 a. shows that at the lower strain range a longer dwell time gives a shorter life, but at the higher strain range the dwell time has none or little effect on the life. The number of cycles to failure for LCF when no dwell time is applied, is shown for both strain ranges in Fig. 2 b. The observations are similar to the results recently reported by Polák et al. [7]. In order to understand why the dwell time has such as different influence on the fatigue life, with respect to applied strain range, the differences in the cyclic behavior needs to be understood.
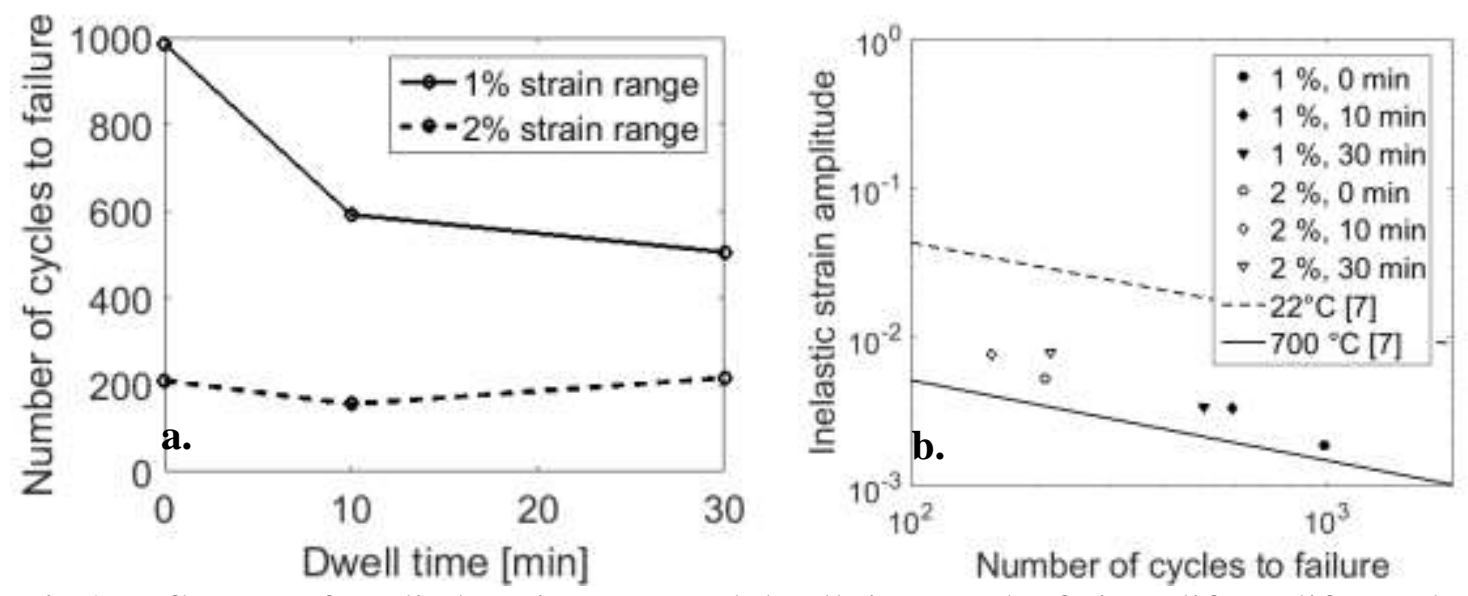

Fig.2: Influence of applied strain range and dwell time on the fatigue life, a. life vs. dwell time, b. inelastic strain vs. life, the lines are taken from Ref. [7].

\subsection{INFLUENCE OF DWELL TIME ON CYCLIC PLASTIC DEFORMATION BEHAVIOR}

In Fig.3 the maximum stress and the number of cycles are displayed for tests with and without applied dwell time and low and high strain ranges. Recently cyclic straining conducted on Sanicro 25 at $700{ }^{\circ} \mathrm{C}$ has been reported to result in pronounced cyclic hardening due to enhanced cross slip and more homogeneous cyclic deformation $[7,8]$ assisted by nano-clusters [8]. Figure 3 a. and c., where no dwell time is applied, shows cyclic hardening. However, when a dwell time is introduced, precipitation and nano-clustering is developed and suggested to be more dominant during the subsequent cyclic deformation. Since the time at elevated temperature is increased, the precipitation of secondary phases, such as $\mathrm{M}_{23} \mathrm{C}_{6}$ and $\mathrm{Cu}$-rich nanoparticles [6], is pronounced. This is also supported by the fact that the maximum stress reaches the highest value after only about 60 cycles when using a 1 $\%$ strain range and a $10 \mathrm{~min}$ dwell time (Fig. 3 b.), compared to when no dwell time is applied, where the maximum stress stabilizes after about four times the number of cycles (Fig.3 a.). For the higher strain range the maximum stress stabilizes or reaches its highest value after approximately the same number of cycles, around 25 cycles, regardless of applied dwell time. This indicates that at the higher strain range it is the same mechanisms that are responsible for the cyclic hardening regardless of dwell time. However, after the initial cyclic hardening the material experiences softening when dwell times are applied. This is most likely a result of stress relaxation during the dwell time and recovery phenomena that become more dominant during the dwell times at elevated temperature. Observations of the 
specimens also indicate that formation of several surface cracks initiated at grain boundaries might contribute to the softening. The cracks were observed, using a stereo light optical microscope, at the specimen surface after the testing for both strain ranges when dwell times were applied. Nevertheless, a significant lower amount of secondary surface cracks was found after the testing when no dwell time was applied for both strain ranges. Thus, during the creep-fatigue interaction tests there are different possible mechanisms active:

- Hardening due to rapid increase in dislocation density [7, 8].

- Hardening due to precipitation and nano-clusters [8].

- Softening due to stress relaxation.

- Softening due to recovery phenomena.

- Softening due to multiple micro-crack initiation on the surface [12].
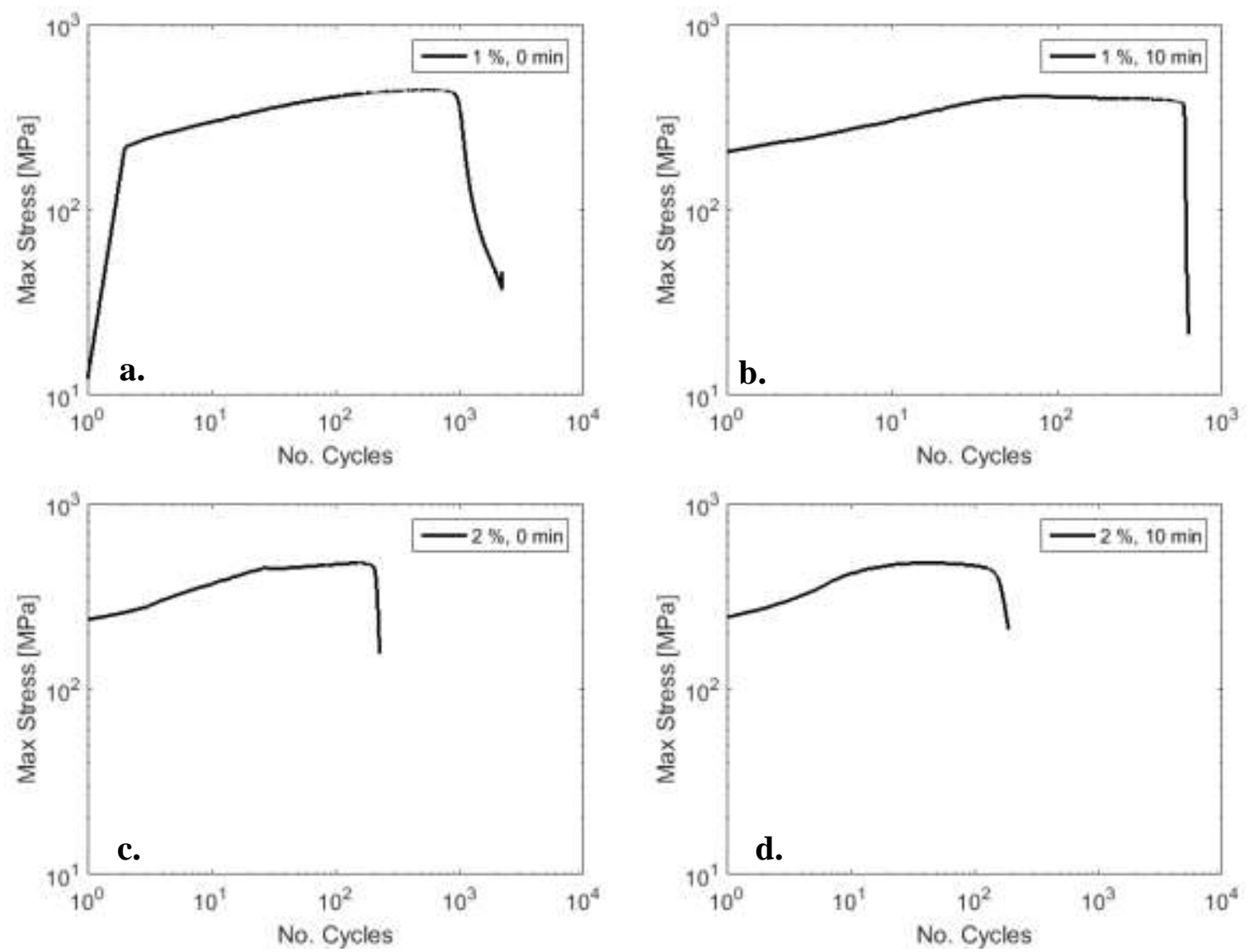

Fig.3: Cyclic hardening/softening curves at $700{ }^{\circ} \mathrm{C}$ with two strain ranges and two dwell times, a. Strain range $1 \%$, dwell time 0 minutes, b. strain range $1 \%$, dwell time 10 minutes, c. strain range $2 \%$, dwell time 0 minutes, d. strain range $2 \%$, dwell time 10 minutes.

\subsection{INFLUENCE OF DWELL TIME ON CYCLIC DEFORMATION}

Figure 4 displays hysteresis loops from the LCF test without (Fig.4 a.) or with 30 min (Fig.4 b.) dwell time. Stress relaxation due to the dwell time is observed at each strain maxima in Fig. 4 b. The low degree of stress relaxation, $36 \mathrm{MPa}$ in tension and $26 \mathrm{MPa}$ in compression, in the first cycle in Fig. 4 b. is attributed to the lower maximum stress levels of the first cycle. As a consequence of the relaxation a larger inelastic strain range occurs, shown in Fig.4. In Fig. 4 the serrations occurring up to the $10^{\text {th }}$ cycle under LCF testing without dwell time and the $1^{\text {st }}$ cycle under testing with applied dwell time are attributed to dynamic strain aging [13]. 

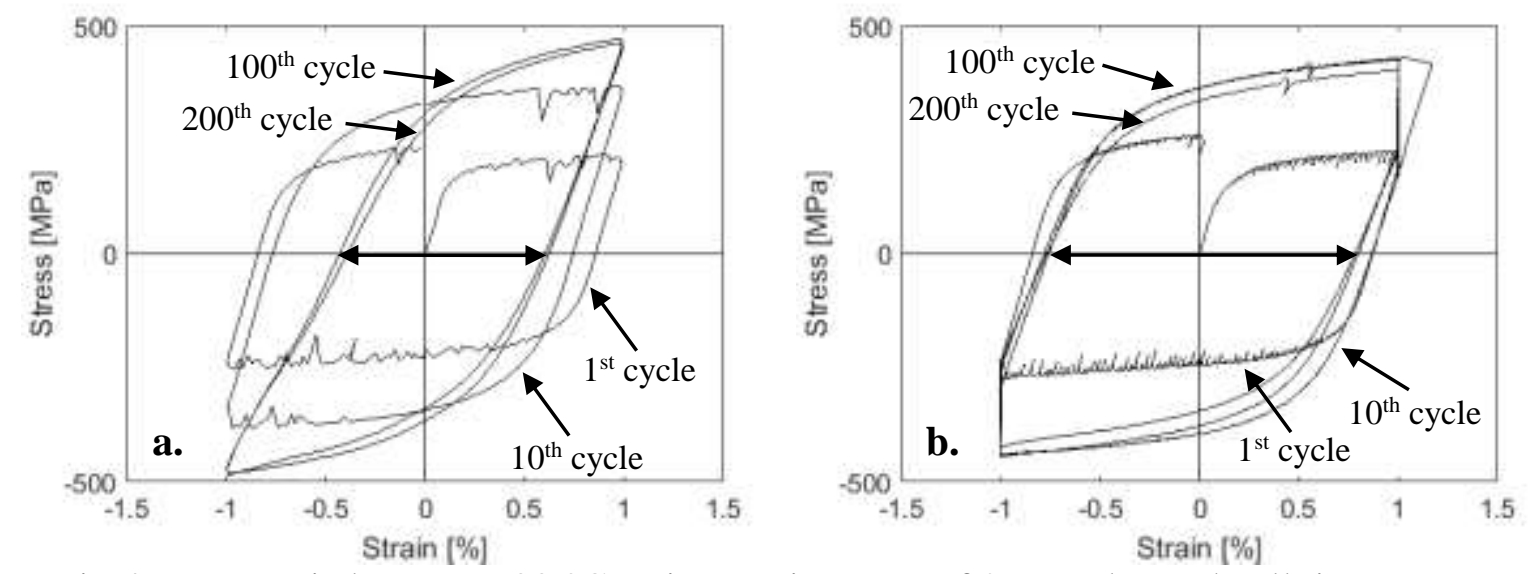

Fig.4: Hysteresis loops at $700{ }^{\circ} \mathrm{C}$, using strain range of $2 \%$ and two dwell times, a. Dwell time 0 minutes, b. dwell time 30 minutes. The inelastic strain ranges corresponding to the $100^{\text {th }}$ cycle are pointed out by the double arrows.

\subsection{DEFORMATION AND DAMAGE BEHAVIOR DURING CREEP-FATIGUE INTERACTION}

Figure 5 shows the microstructural development in the cross-section after failure from different dwell times and strain ranges. The concentration of strain and damage mainly occurred at grain boundary triple junctions. For the specimen without dwell time, plastic strain can be observed in grains or at grain boundaries (Fig.5 a.). With increasing dwell time (Fig.5 b. and c.), some grains appeared recovered or less deformed (Fig.5 b.-d.). This type of grains increases with dwell time. The recovery relates an higher increase in the inelastic strain range with dwell time for the tests with lower total strain range compared to test with higher total strain range. Since an increased recovery during the dwell time will give a larger stress relaxation, shown in Fig.4 b., this will lead to an increased inelastic strain range.

In the specimen without dwell time, areas with high plastic deformation were found around (Fig.6 a.) and in front (Fig.6 b.) of the crack. When dwell time was applied more intregranular cracking (Fig.6 c.) and less plastic deformation in the front of the cracks were observed (Fig.6 d.). The cracks can be attributed to stress relaxation and precipitation at grain boundaries. The intergranular cracking will contribute to a lower degree of plastic deformation around the cracks. The lower plastic deformation in the front of the cracks is probably due to dislocation relief when the dwell times are applied.

In the specimens without applied dwell time deformation twins were found close to the crack, shown in Fig.7. The formation of twins is due to the high stress level associated with the high plastically deformed areas. Since the dwell time leads to recovery, twining is less prone to occur in the specimens with applied dwell time. 


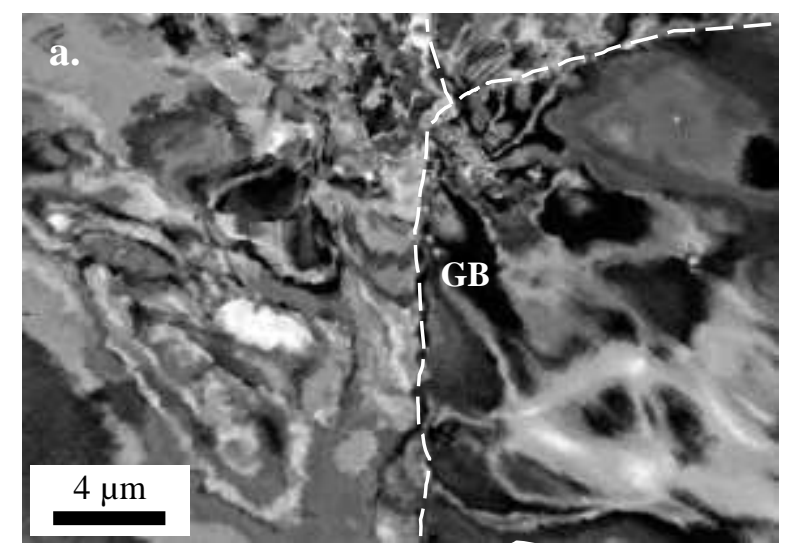

$40 \mu \mathrm{m}$

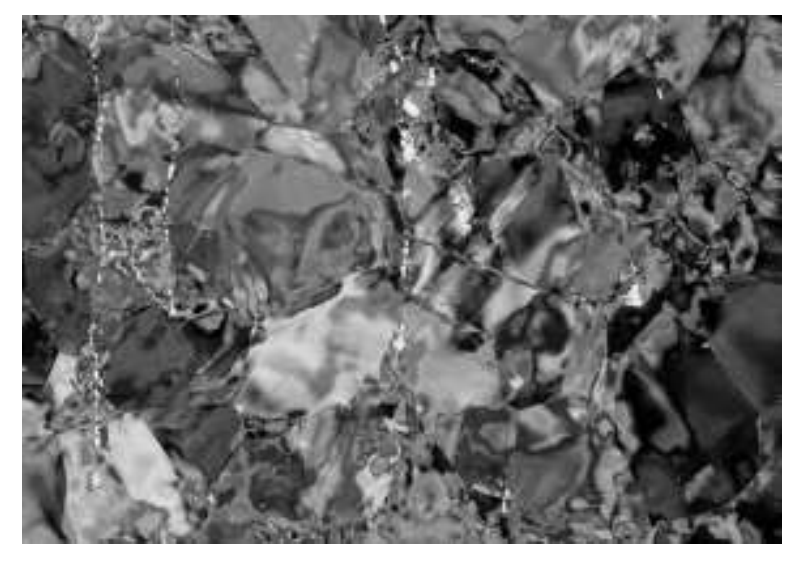



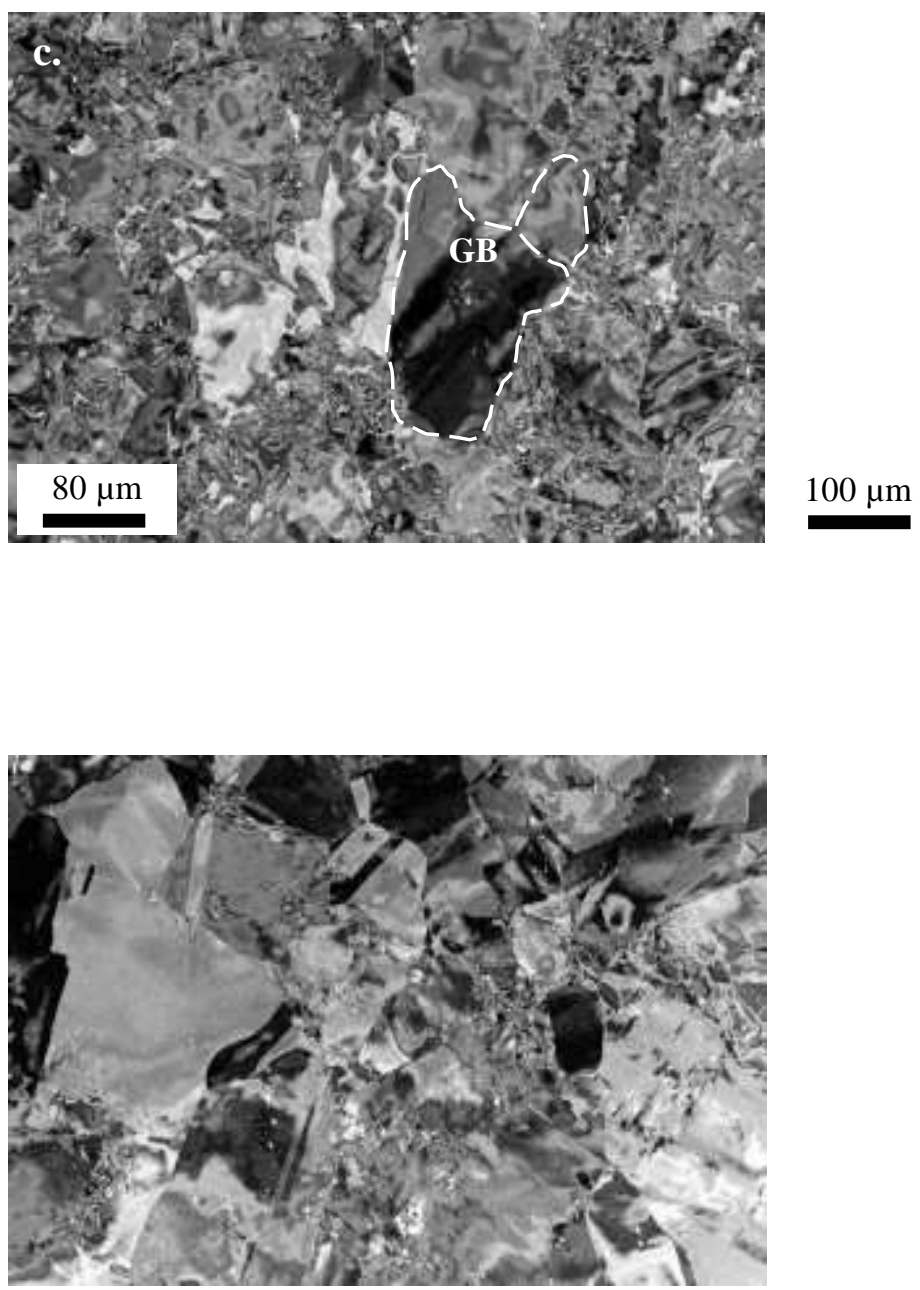

Fig.5 ECCI micrographs after fracture, a. Strain range $2 \%$, dwell time 0 minutes, b. strain range $2 \%$, dwell time 10 minutes, c. strain range $2 \%$, dwell time 30 minutes, d. strain range $1 \%$, dwell time 30 minutes. GB means grain boundaries. The load axes are vertically in the pictures.
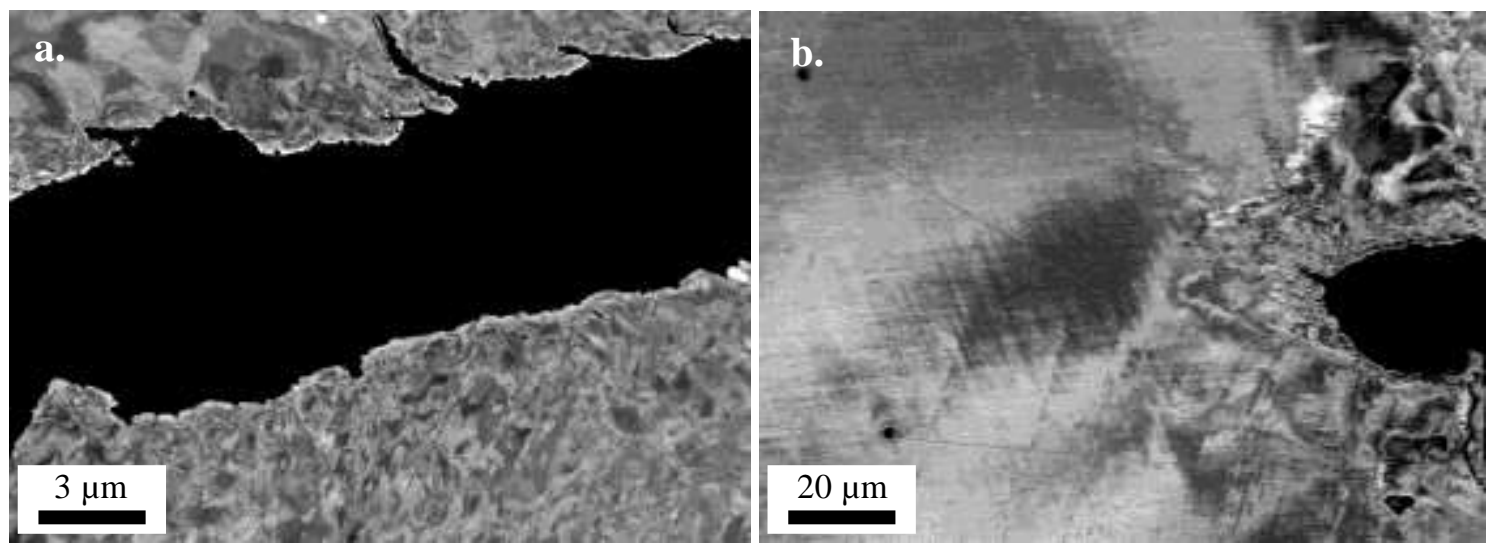

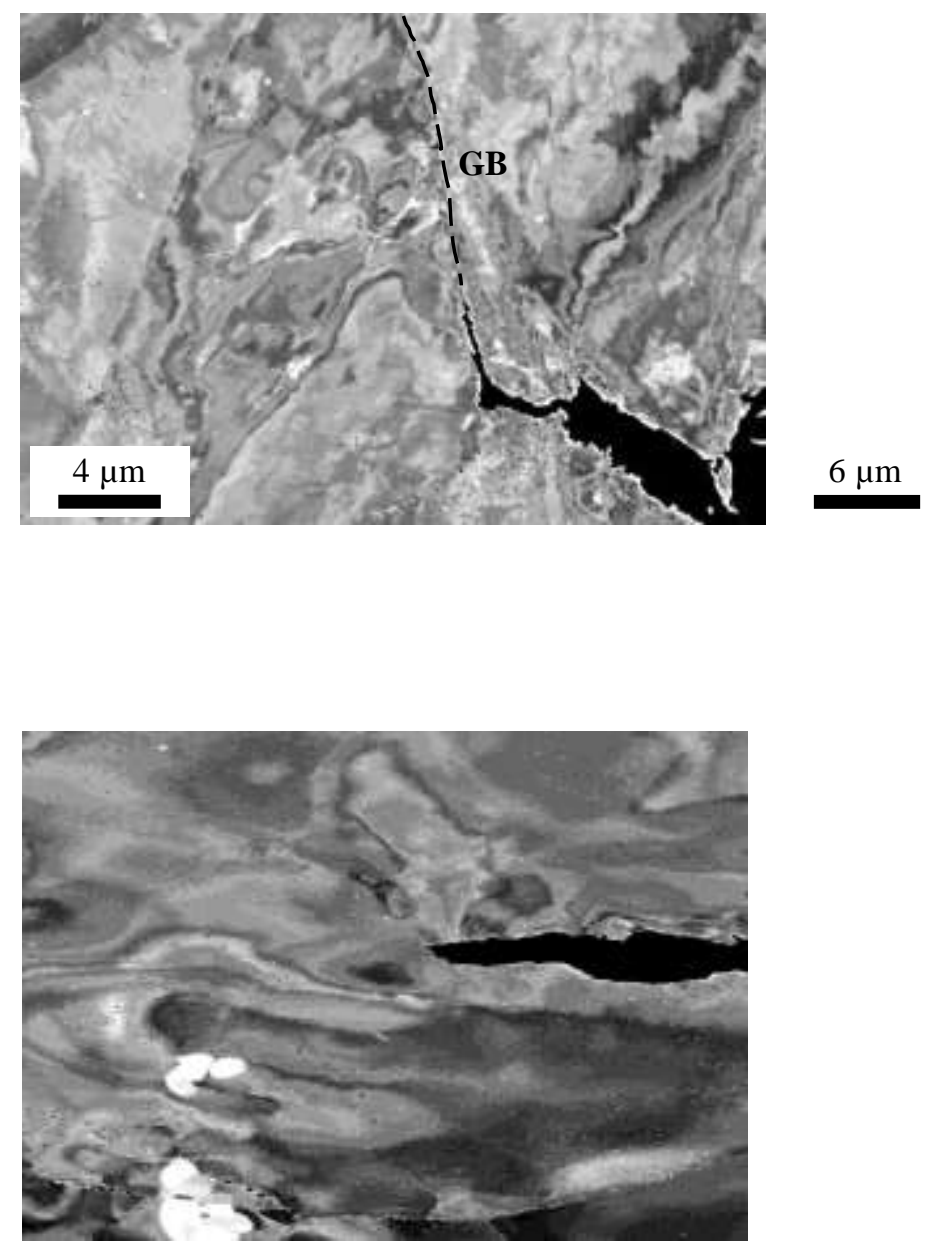

Fig.6: ECCI micrographs of crack and crack tips after fracture, a-b. Strain range $2 \%$, dwell time 0 minutes, c. strain range $2 \%$, dwell time 10 minutes, d. strain range $2 \%$, dwell time 30 minutes. GB means grain boundaries. The load axes are vertically in the pictures. 

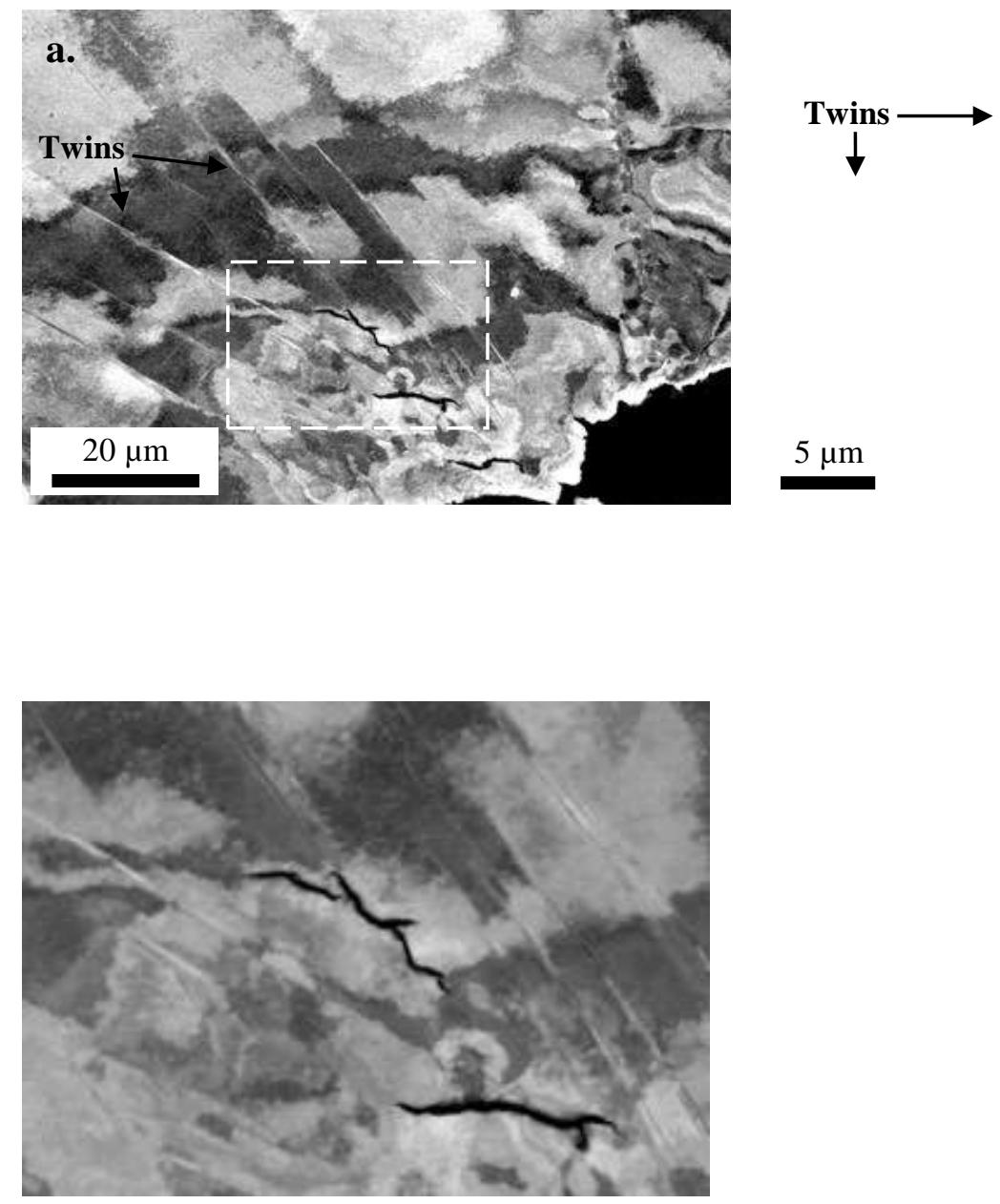

$5 \mu \mathrm{m}$

Fig.7: ECCI micrograph of cross-section, showing twins in a specimen from the strain range of $2 \%$ and without dwell time where b. is a magnification of the area marked in a. The load axes are vertically in the pictures.

\subsection{CRACK PROPAGATION}

From the fracture investigation of the cross-section it was found that the introduction of dwell time results in more intergranular cracking and crack deflection. In Fig. 8 two main crack paths are shown, propagating from the specimen surface and into the material. As can be seen in Fig. 8 the crack shows less intergranular propagation and crack deflection when no dwell time is applied (Fig.8 a. and b.), compared to the crack with a dwell time (Fig.8 c. and d.). Intergranular crack propagation due the grain boundary precipitation can be one of the reasons. 


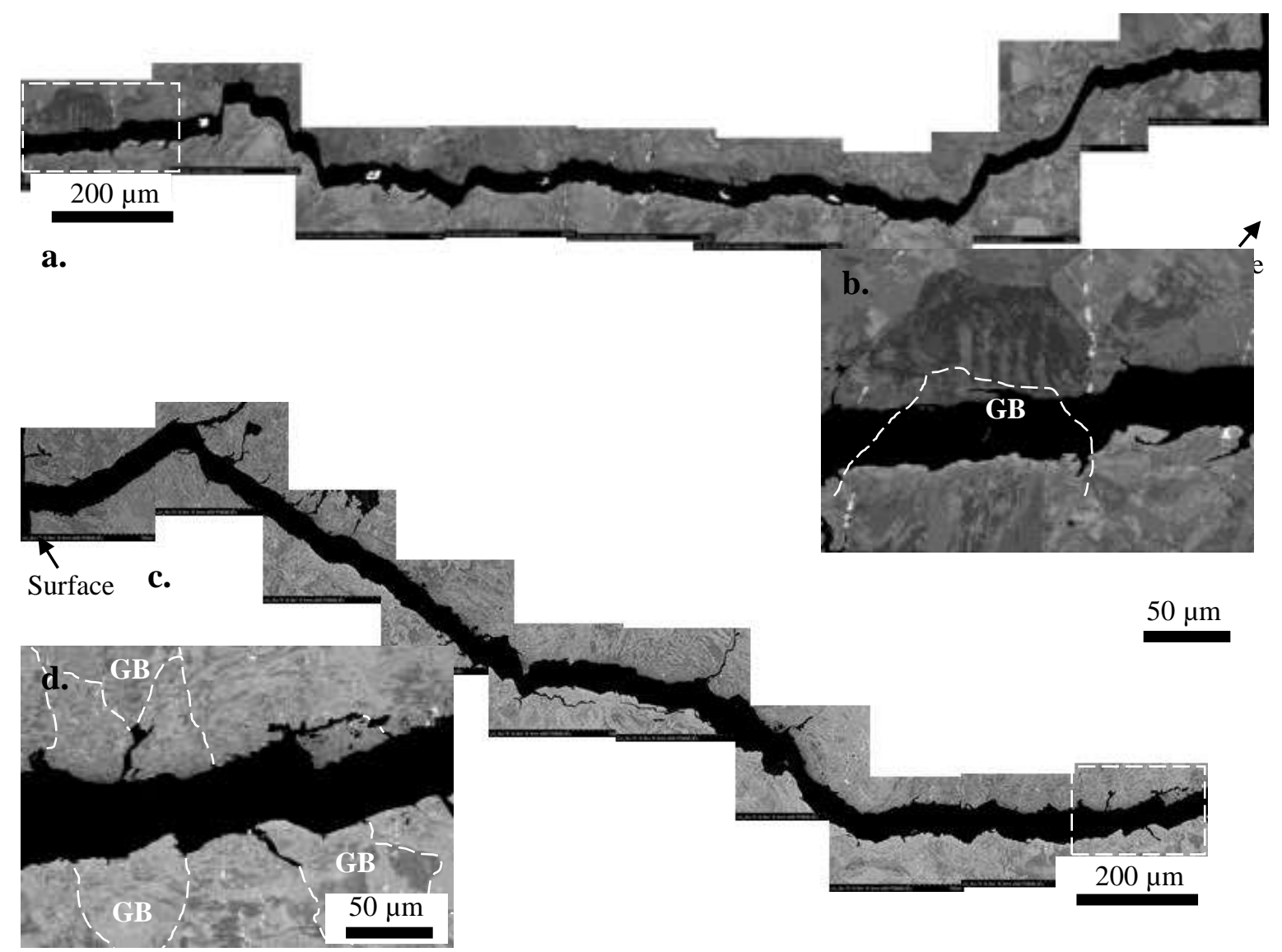

Fig.8: The influence of dwell time on crack propagation, the main cracks at, a. Strain range 1 $\%$, dwell time 0 minute, b. magnification of the marked area in a., c. strain range $1 \%$, dwell time 30 minutes and d. magnification of the marked area in c. The load axes are vertically in the pictures.

\subsection{CONCLUSIONS}

Creep-fatigue interaction tests have been conducted on a Sandvik Sanicro ${ }^{\mathrm{TM}} 25$ austenitic stainless steel at $700{ }^{\circ} \mathrm{C}$. The influence of dwell time on the cyclic deformation behavior and life time has been evaluated. The results show that the introduction of dwell time causes a larger plastic strain range. The results also show that dwell time gives a shorter life at a lower strain range, but has no or small effect on the life at a higher strain range. Fracture investigation shows that dwell time results in more intergranular cracking.

\section{ACKNOWLEDGEMENTS}

Present study was financially supported by AB Sandvik Materials Technology in Sweden and the Swedish National Energy Administration through the Research Consortium of Materials Technology for Thermal Energy Processes, Grant No. KME-701. Agora Materiae and AFM Strategic Faculty Grant SFO-MAT-LiU\#2009-00971 at Linköping University are also acknowledged. The assistant work with some of the ECCI pictures by Mr Jerry Lindqvist and the fruitful scientific discussions with Lic. M.Sc. Viktor Norman are appreciated. 


\section{REFERENCES}

1. T. B. Gibbons, Trans.Indian.Inst.Met., 66 (2013) 631.

2. R, Blum, R.W. Vanstone and C. Messelier-Gouze, Proc. 4th Int. Conf. on Adv. in Mater. Technol. for Fossil Power Plant, (2004), p.116, Hilton Head Island, South Carolina, US.

3. R. Viswanathana, K. Colemana and U. Rao, Int.J.Pres.Ves.Pip., 83 (2006) 778.

4. R. Rautio and S. Bruce, Proc. 4th Int. Conf. on Adv. in Mater. Technol. for fossil power plants, (2004), p.274, Hilton Head Island, South Carolina, US.

5. G. Chai, J.O. Nilsson, M. Boström, J. Högberg and U. Forsberg, Proc. of ICAS 2011, (2010), p.56. Guilin lijiang waterfall hotel, Guilin City, China

6. G. Chai, M. Boström, M. Olaison and U. Forsberg, Procedia.Eng., 55 (2013) 232.

7. J. Polák, R. Petráš, M. Heczko, T. Kruml and G. Chai, Mat.Sci.Eng.A., 615 (2014) 175.

8. J. Polák, R. Petráš, M. Heczko, T. Kruml and G. Chai, Int.J.Fatigue, In Press: doi:10.1016/j.ijfatigue.2015.03.015.

9. S. Johansson, J. Moverare and R. Peng, Prakt.Metallogr.-Pr.M., 50 (2013) 810.

10. I. Gutierrez-Urrutia, S. Zaefferer and D Raabe, JOM, 65 (2013) 1229.

11. S. Zaefferer and N-N Elhami, Acta.Mater., 75 (2014) 20.

12. G. V. Prasad Reddy, R. Sandhya, S. Sankaran, P. Parameswaran and K. Laha, Mater.Design. 88 (2015) 972.

13. G. Chai, Adv.Mat.Res., 891-892 (2014) 377. 